\title{
CHITOSAN NANOPARTICLES SUPPRESS THE OXIDATIVE STRESS IN SUBMANDIBULAR SALIVARY GLANDS AND PREVENT THE GENOTOXICITY OF MONOSODIUM GLUTAMATE IN ALBINO RATS: HISTOLOGICAL, IMMUNOHISTOCHEMICAL AND CHROMOSOMAL ABERRATIONS ANALYSIS STUDY
}

\author{
Elham F. Mahmoud*, Mahmoud F. Mahmoud** and Enas Hegazy***
}

\begin{abstract}
Aim of the study: The goal of the current study was to evaluate the protective impact of chitosan nanoparticles (COS-NPs) against monosodium glutamate (MSG)-induced oxidative stress in submandibular salivary glands and genotoxicity of bone marrow chromosomes.

Material and methods: 30 adult male albino rats were randomly divided into three equal groups and treated orally for 24 days as follow: Group I the (control) group, group II (MSG-treated group): each rat received a daily MSG at a dose of $(400 \mathrm{mg} / \mathrm{Kg}$. b. w.) and group III: (MSG + COS-NPs treated group): rats treated orally with monosodium glutamate $(400 \mathrm{mg} / \mathrm{kg}$. b. w.) then the chitosan nanoparticles ( $280 \mathrm{mg} / \mathrm{kg}$ b. w.) respectively was administered to rats daily by oral gavage. After 24 days, both sides of the submandibular salivary glands were excised, processed and finally inspected histologically and immunohistochemically. Bone marrow was obtained from both femora of rats, 500 well spread metaphases per each animal were checked microscopically for both structural and numerical chromosomal aberrations.
\end{abstract}

Results: The submandibular salivary glands (SMSG) of MSG treated rats revealed severe histopathological changes, moderate to strong granular cytoplasmic reaction of caspase-3 immunoreactivity in the acinar and ductal cells. And increase in the frequency of structural and numerical chromosomal aberrations of bone marrow cells. Chitosan nanoparticles (COSNPs) exhibited significant amelioration in histological and immunohistochemical picture in the submandibular salivary glands of MSG treated rats. Also chitosan nanoparticles could significantly inhibit the chromosomal aberrations and succeeded to neutralize the MSG genotoxic effects in bone marrow cells of rats.

Conclusion: It could be concluded that COS-NPs have potential antioxidant effect that protect against cytotoxicity and genotoxicity induced by MSG in rats.

KEYWORDS: MSG; SMSG; caspase 3; chromosomal aberration; COS-NPs.

\footnotetext{
* Associate Professor, Oral Biology Department, Faculty of Dentistry, Suez Canal University, Egypt.

** Associate Professor, Biological and Geological Sciences Department, Faculty of Education, Ain Shams University, Egypt.

*** Lecturer of Oral Biology, Oral Biology Department, Faculty of Dentistry, Suez Canal University, Egypt.
} 


\section{INTRODUCTION}

Recently for preservation or improvement of food taste, the food additives are most commonly used $^{(31,3)}$. Monosodium glutamate (MSG) is widely consumed in most fast food-stuffs as a flavor enhancer like packed chicken, botanical burgers, chips, hot dog, marinated meats, broth, appetizers and frosted meals ${ }^{(7,65)}$. MSG is the most common naturally occurring nonessential amino acid and is the salt form of L - glutamic acid ${ }^{(63)}$. Monosodium glutamate consists of $78 \%$ glutamic acid, $22 \%$ sodium and water ${ }^{(49)}$. It is metabolized in liver and excreted via the kidney ${ }^{(51)}$. Glutamic acid is converted into lactate in liver and alanine in intestinal mucosa ${ }^{(6)}$. Glutamate is an essential ingredient of several proteins and peptides of the majority of tissues. Normally, glutamate is generated in the body and reveals a fundamental function in human metabolism. When MSG is added to food, it produces a flavoring action resembling to the naturally occurring free glutamate that vary from the four traditional tastes of sweet, bitter, salty and sour ${ }^{(27)}$. The flavoring effect of MSG that impacts the appetite favourably is occurred via its motivation of the orosensory receptors and through enhancing the savory of meals, but although its taste motivation and appetite improvement, reports mentioned that MSG is toxic for human and experimental animals and induces weight gain (5). Nowadays, MSG was utilized as a whitening agent for elimination of spots from dressings and its bleaching action could be deleterious or injurious to the stomach mucosa ${ }^{(11)}$. Its powerful bleaching impacts were equivalent to the effects of hydrogen peroxide on the bones ${ }^{(19)}$. Some studies reported that, there was a high risk of fatty and fibrotic liver in male rats treated orally with MSG (60-100mg) daily for one month ${ }^{(59)}$. As well as, intake of high doses of MSG leads to elevation of the liver and renal functions level ${ }^{(38,56)}$. Prolonged administration of MSG could yield manifestations like migraine, fatigue, vertigo, perspiring, tingling, and redness. Moreover, consumption of MSG has been supposed to result severe cases, involving cardiac arrhythmia, neuropathy, urticaria, asthma, cutaneous allergic reactions, and abdominal disturbances ${ }^{(13)}$. It was reported that MSG male treated rats revealed infertility through testicular hemorrhage, inhibition of spermatogenesis, reduction the number of sperms and further sperm aberrations ${ }^{(36)}$. While Female rats treated with MSG developed infertility via estrus cycle disorders, follicular degeneration of ovaries and elevated estrogen and progesterone hormone levels in MSG-treated female rats $(7,12,66)$. Persistent consumption of high quantities of MSG in fashionable nutrition can elevate the oxidative stress and reduce the antioxidant enzyme activities mainly by generation of reactive oxygen species (ROS), lead to cytotoxicity in multiple tissues in the body ${ }^{(42,52)}$. The average lethal dose (LD50) of MSG taken orally in the mice and rat is extremely high, between 10 and $20 \mathrm{~g} / \mathrm{kg}$ bodyweight and the greatest tolerable dose of MSG in humans is about $60 \mathrm{mg} / \mathrm{kg}$ body weight. MSG nutritional levels up to $4 \%$ in the food did not show any harmful impacts in rats and mice ${ }^{(23)}$.

One of the naturally occurring polysaccharides is Chitosan (COS). It could be obtained from deacetylation of chitin of insects exoskeleton and crustacean shells. Because of its indigestibility by digestive enzymes, chitosan classified as a dietary fiber ${ }^{(25)}$. Chitosan played an important role in the food preservation field and performed multiple obvious activities in the microbial alleviating, biomedicinal and pharmaceutical products. Chitosan has other biological activities like antioxidant ${ }^{(9)}$, antitumor features in human liver ${ }^{(50)}$ and free radical scavenging activity in vivo and ex vivo ${ }^{(20,16)}$. The antitumor activities of chitosan through direct intervention with the tumor cell metabolism where it prevents cell growth and/ or stimulates cell apoptosis and/or via upgrading the body's immunity ${ }^{(8)}$. It was found that chitosan possess antihypertensive, chemopreventive and immuno-potentiating impacts in colon cancer $^{(33)}$, antimicrobial $^{(39,62)}$, antiviral activity ${ }^{(17)}$ and antifungal 
activities ${ }^{(57)}$. Due to biocompatible, biodegradable and nontoxic properties of chitosan, it can be used in biosensors ${ }^{(29)}$. But, the high molecular weight and water-insolubility of COS leads to limitation of its applications. Recently, various researches have concentrated on the preparation of chitosan nanoparticles (COS-NPs) that delivers a sensible pharmaceutical base to promote the efficiency of oral bioavailability and the curative effect of COS and other weakly soluble drugs ${ }^{(21)}$. COSNPs display premium properties when compared to regular COS to improve the immune impact, the antimicrobial and the anticancer efficiency $(1,10)$. Moreover, nanoparticles have a harder bending surface when compared to large chitosan particles; this yields more disintegration pressure and consequently increase in saturation solubility ${ }^{(40)}$. Recently, as a drug delivery system, studies revealed that chitosan nanoparticles can bear several drugs involving gene drugs, anticancer chemical drugs, protein drugs, antibiotics through multiple routes of administration; oral, nasal, ocular, and intravenous due to their well biocompatibility, good degradability and nontoxicity ${ }^{(47)}$.

Therefore, the aim of the present study was to assess the possible protective and preventive effects of chitosan nanoparticles (COS-NPs) against monosodium glutamate (MSG) induced chromosomal aberrations (genotoxicity) and submandibular salivary glands cytotoxicity in rats; histologically and immunohistochemically.

\section{MATERIALS AND METHODS}

\section{Chemicals and Kits}

\section{Monosodium Glutamate (MSG)}

Mono-sodium glutamate was obtained from El Dawlia for Medical Equipments and Chemicals Co. Cairo/Egypt. In the form of white colored powder soluble in water. It was dissolved in distilled water before use.

\section{Chitosan}

Chitosan was obtained from Sigma-Aldrich (France), was available in the highest analytical grade.

\section{Preparation and characterization of Chitosan Nanoparticles (COS-NPs)}

Preparation of COS-NPs was done depending on the technique illustrated by Abdel-Wahhab et al. ${ }^{(1)}$ and Tang et al., ${ }^{(54,55)}$. Dynamic light scattering (DLS; Zetasizer ${ }^{\mathrm{TM}}$ 3000E, Malvern Instruments Worcestershire, UK) was used for determination of particle sizes. COS-NPs were obtained by freezedrying, all measurements were carried out in triplicate.

\section{Experimental animals}

30 adult male albino rats weighing $200 \pm 20$ gram/each were used in this study. The animals were purchased from the animal house, Faculty of medicine, Cairo University. Before the experimental work, the rats were acclimatized in the laboratory for one week. Animals were inhabited in a temperature and light-controlled room (12-h light/dark cycle), with ordinary rodent chow and tap water ad libitum.

\section{Experimental design}

All experimental procedures were accomplished in accordance with the guidelines of the Institutional Animal Care and Use Committee of Faculty of Medicine; Cairo University.

The rats were indiscriminately divided into three equal groups ( $\mathrm{n}=10$ rats):

Group I (Control): Each rat received orally $2 \mathrm{ml}$ distilled water daily.

Group II (MSG-treated group): Each rat received a daily oral dose of MSG (400mg/Kg. body weight) for 24 days according to previous studies ${ }^{(15)}$.

Group III: (MSG + COS-NPs treated group): Rats treated orally with monosodium glutamate (400 mg/kg. b. w.) then the chitosan Nanoparticles 
(280 mg/kg b. w.) respectively was administered to rat daily by oral gavage.

During the whole experimental period, the rats were noticed daily for any signs of toxicity. At the end of the study period (day 24), all rats were killed by cervical dislocation, and the submandibular salivary gland (SMG) of both sides were excised and processed for histological and immunohistochemical inspection by light microscope.

\section{For light microscopic study:}

SMG tissues were fixed in $10 \%$ neutral buffered formalin for $24 \mathrm{~h}$, washed, dehydrated and cleared to be embedded in paraffin. Then, paraffin sections (4-5 microns thickness) were sliced then stained by hematoxylin and eosin ( $\mathrm{H} \& \mathrm{E})$ for histological examination and immunohistochemical staining using monoclonal antibodies to cleaved caspase-3 for immunohistochemical examination.

\section{Caspase-3 staining assessment:}

The histological sections were inspected by light microscope to evaluate the incidence of positive cells. Positive Caspase-3-labelled cells were determined by brown cytoplasmic staining ${ }^{(18)}$.

\section{Immunohistochemical statistical analysis:}

Quantitative data of the image analyzer were statistically assessed and introduced as means and standard deviation (SD) values. For compare mean values of caspase-3 immunoexpression related parameters in the studied groups, ANOVA (analysis of variance) test was used. A probability value ( $p$ value) less than 0.05 was considered statistically significant.

\section{Bone Marrow Chromosomal preparations:}

The approach used for chromosomal preparation from the bone marrow cells was depended on the technique described by Preston et al. ${ }^{(45)}$ with some modifications. Briefly; whether the animal was treated with the drug or acted as control, each animal was injected with $0.5 \mathrm{mg} / \mathrm{kg}$ Colchicine $2 \mathrm{~h}$ before killing. Both femora were immediately removed after the animals were killed by cervical dislocation then the metaphase spreads were prepared from the bone marrow. Obtained chromosomes were stained in phosphate buffered Giemsa.

\section{Metaphase scoring:}

500 well spread metaphases per each animal were inspected microscopically for chromosomal aberrations. Only cells with good spread chromosomes were chosen for scoring. All metaphase spreads, were examined for both structural and numerical aberration ${ }^{(22)}$.

\section{Statistical analysis for Chromosomal aberrations}

The obtained data was revised by SPSS version 16.0 for windows (2007). Each treatment group was compared with the control group with independent samples T- test. The chromosomal aberrations were analyzed and expressed as mean and the standard deviation (mean $\pm \mathrm{SD}$ ). Histograms of cytogenetic data were drawn using Excel 2010. The result was considered to be significant when $\mathrm{P}$ is $\leq 0.05$ and highly significant when $\mathrm{P}$ is $\leq 0.001$.

\section{RESULTS}

\section{Light microscopic results:}

\section{Histolohical results:}

\section{Control group:}

The histological sections of the submandibular salivary glands of control group showed that the gland is mostly consisted of seromucous acini, intercalated, striated, and excretory ducts, granular convoluted tubules (GCTs) and connective tissue stroma. The pyramidal cells of spherical shaped acini appeared with basophilic cytoplasm and rounded basally located nuclei. The intercalated ducts were difficulty detected by light microscope, have low cuboidal cells with basophilic cytoplasm and centrally situated rounded nuclei. The granular 
convoluted tubules (GCTs) revealed tall columnar cell lining having large rounded basally located nuclei with apical eosinophilic granules. The striated ducts appeared lined by columnar cells with centrally located rounded nuclei and extensively eosinophilic cytoplasm with characteristics basal striations. While the excretory ducts were lined by pseudostratified columnar epithelium, generally located adjacent to variable sized blood vessels (Fig. 1A, B, C).

\section{MSG-treated group:}

$H \& E$ stained sections of the submandibular salivary gland of monosodium glutamate treated rats, showed signs of acini degeneration, missing of regular structure of the secretory portions and destruction of cytoplasm. Some acini lost their normal circular arrangement with ill- defined boundaries, others exhibited total degeneration and were entirely lost leaving massive vacuoles. The acini and intralobular ducts lost their adhesin in most areas of the gland. The acinar cells demonstrated nuclei with various sizes and shapes appeared in the form of large, hyperchromatic, pleomorphic and some pyknotic nuclei, also many mitotic figure were observed with increased nuclear cytoplasmic ratio were clearly obvious and some giant nuclei were also seen. Most of the GCTs revealed with ill- defined border, degenerated, high eosinophilia and clustering of the granular content. The excretory ducts exhibited irregular forms, epithelial lining losing their pseudostratification, some flattened disfigured cells and apically displaced nuclei. The blood vessels appeared distended and congested with blood next to the excretory ducts (Fig. 2 a,b,c).

\section{MSG + COS-NPs treated group:}

Submandibular salivary gland of chitosan nanoparticles plus monosodium glutamate treated group showed significant improvement in acinar and ductal cells compared to the monosodium glutamate group. The acini returned their uniformity and regularly structured. The inter and intralobular ducts showed normal architecture and proper alignment (Fig. 3 a,b,c).

\section{Immunohistochemical results}

Immunohistochemical examination to detect the cellular apoptosis in rat submandibular salivary glands of group I showed negative caspase-3 immunoreactivity in the secretory portions as well as in the duct cells, while group II showed moderate to strong granular cytoplasmic reaction of caspase- 3 immunoreactivity in the acinar and ductal cells. Immuno-reactivity for caspases-3 was appeared faint in the cytoplasm of group III (Fig. 4A, B, C).

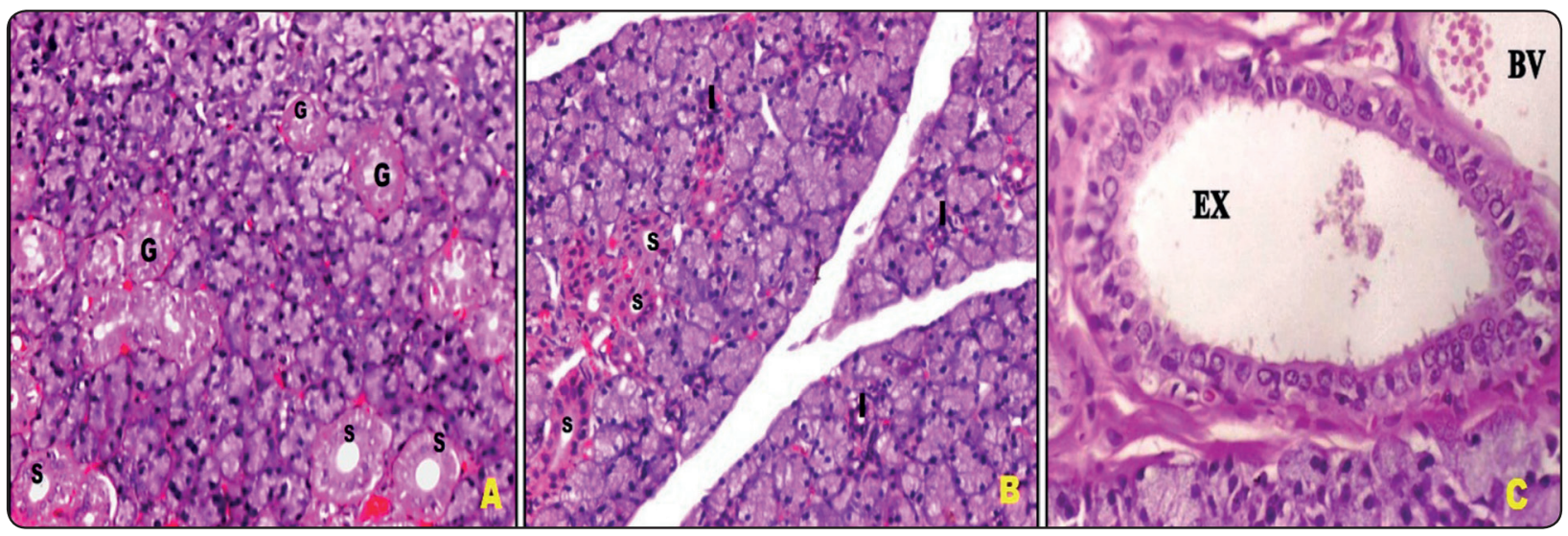

Fig. (1) (A,B,C) Photomicrographs of the control SMSG showing: normal histological features of acini, striated ducts (S), GCTs with normal architecture (G), intralobular intercalated ducts (I) and blood vessel (BV) adjacent to an excretory duct with normal pseudostratified columnar epithelial lining (EX). (H\&E X 400). 


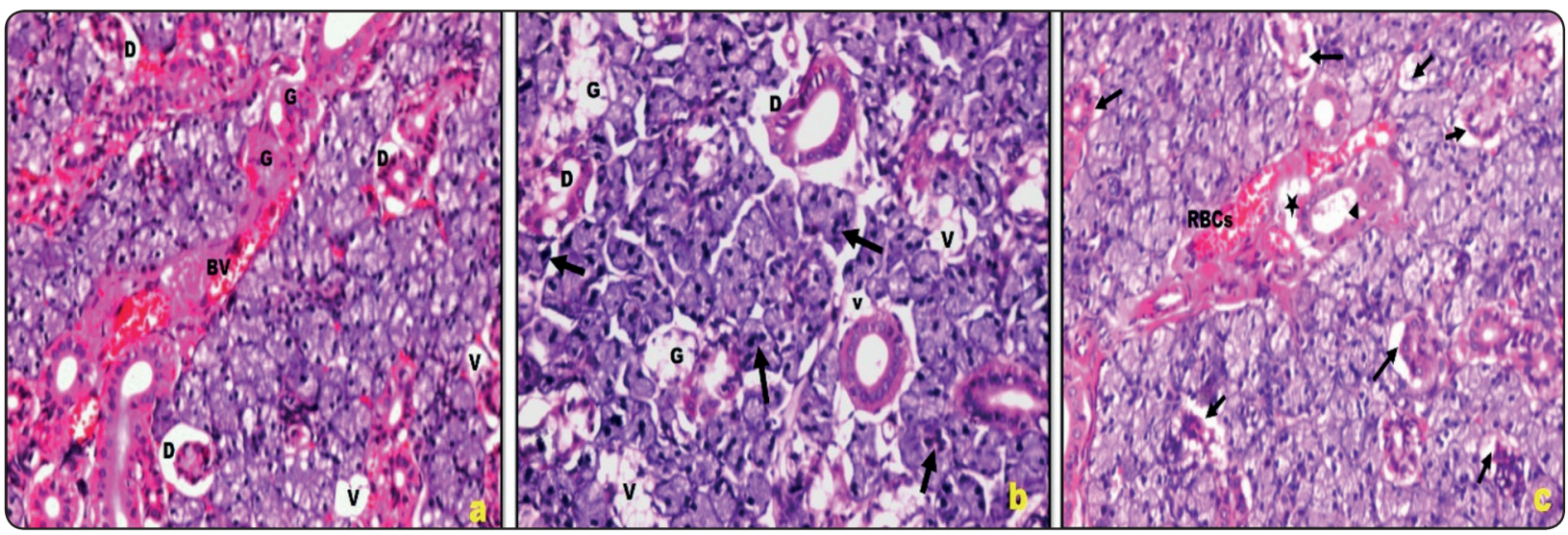

Fig. (2): A photomicrograph of SMSG of MSG treated group (II) showing:(a) degenerated GCTs (G) with increased eosinophilia, degenerated striated ducts (D), multiple vacuoles (V). (b) ill-defined acini, degenerated ducts leaving large multiple vacuoles (v), hyperchromatic and pleomorphic nuclei (arrows). (c) degenerated ducts (arrows), excretory duct with signs of hydropic degeneration (arrow head), loss of pseudostratification (*)and blood vessel congested with blood (RBCs). (H\&E X 400).

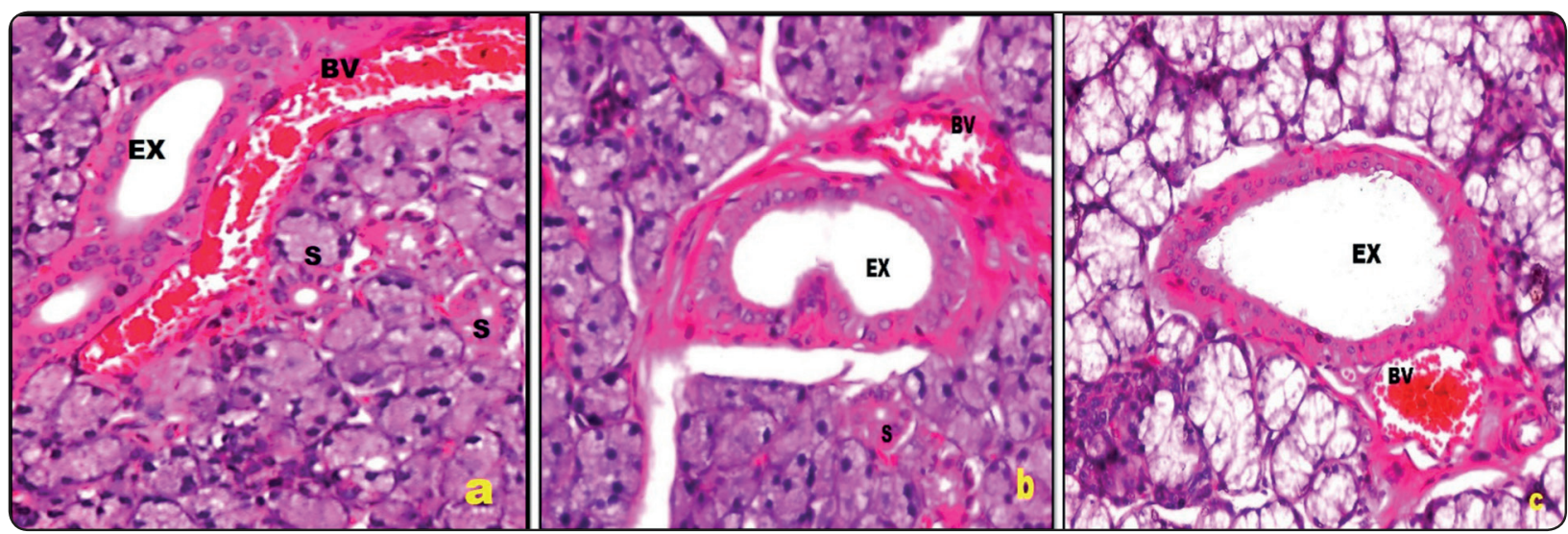

Fig.3 (a, b, c): A photomicrograph of SMSG of MSG + COS-NPs treated group (III) showing: nearly normal architecture and proper alignment of acinar and ductal cells. (H\&E X 400).
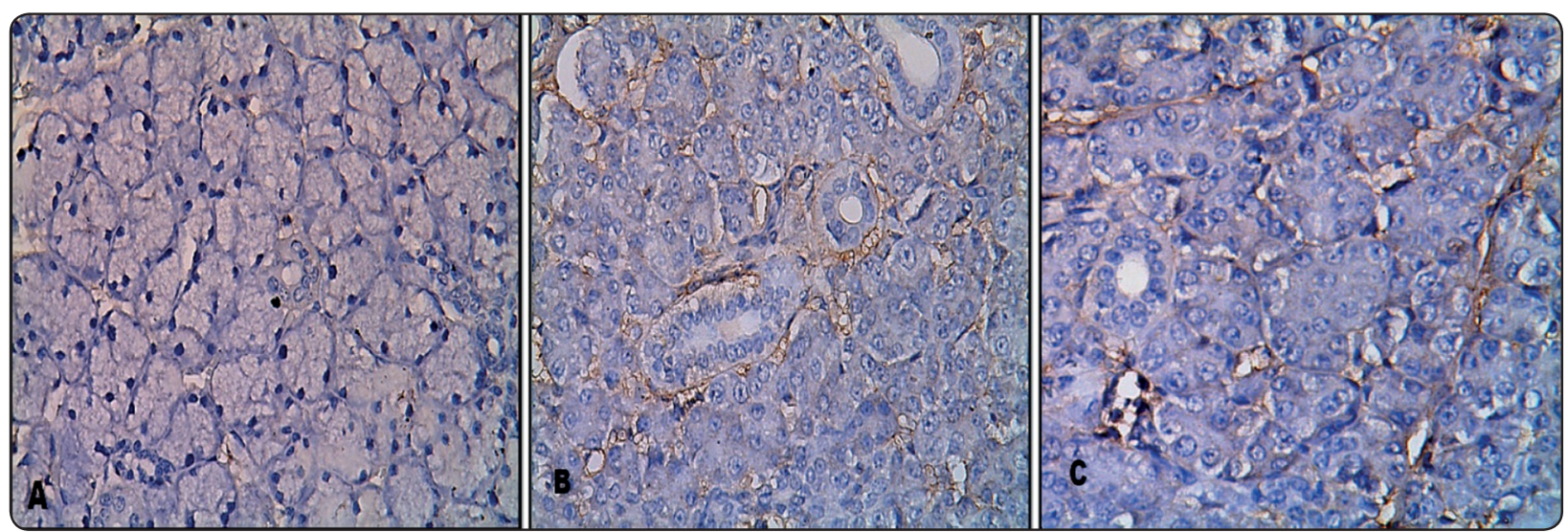

Fig. (4) A photomicrograph showing negative caspase-3 immunoexpression of group I in either nuclei or cytoplasm of the acinar and ductal cells (A). strong caspase-3 immunoexpression in the cytoplasm in the secretory portions and in the duct cells of group II (B). faint Immuno-reactivity for caspases-3 in the cytoplasm of group III (C). (original magnification, x 400). 


\section{Statistical analysis for Immunohistochemical results}

The optical density of areas occupied by active caspases-3 in the rat submandibular salivary glands of the control and experimental groups is summarized in Table 1, Fig.5. elevation of the optical density of caspases-3 was obvious in the cytoplasm of both of the acinar and ductal cells of the experimental group II and was statistically evaluated to be highly significant.

Table (I): Showing the difference in mean Caspase-3 optical density of the different groups using ANOVA Test.

\begin{tabular}{|c|c|c|c|}
\hline \multirow{2}{*}{ Group } & \multicolumn{3}{|c|}{$\begin{array}{r}\text { Caspase-3 optical density of the rat } \\
\text { submandibular salivary glands }\end{array}$} \\
\cline { 2 - 3 } & $\mathrm{M} \pm \mathrm{SD}$ & F-Value & p-Value \\
\hline Group I & $44.32 \pm 1.34$ & 16.17 & $<0.002^{* *}$ \\
\hline Group II & $51.76 \pm 1.26$ & & \\
\hline Group III & $46.06 \pm 1.50$ & & \\
\hline
\end{tabular}

${ }^{* * *}$ High significant difference at $(p<0.01)$.

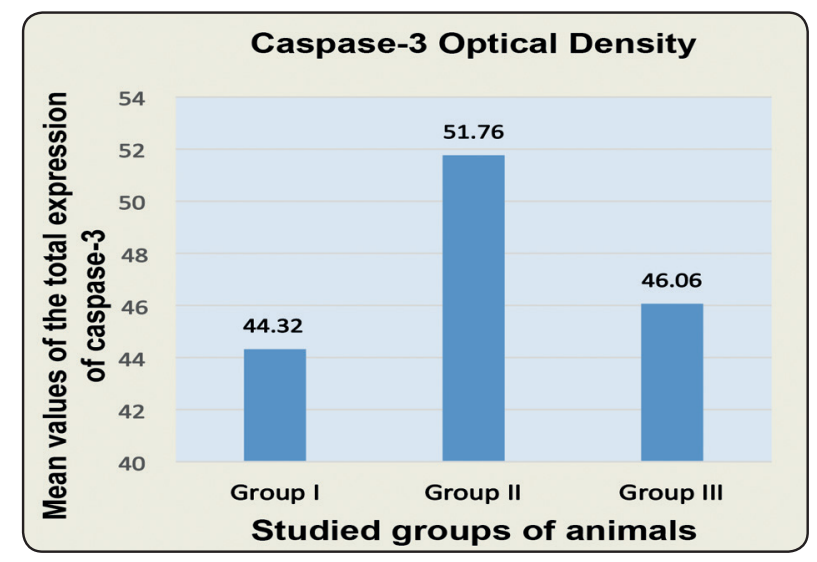

Fig. (5): A bar chart illustrating the statistical difference in the mean values of overall expression of caspase 3 among the studied groups.

\section{Chromosomal aberration analysis}

Group I (Control group): The diploid number of adult albino male rat is $2 n=38+X Y$. The chromosomes of the control rats are telocentric and their lengths forming a continuous series (Fig. 6 A).

Group II (MSG-treated group): The chromosomes of the bone marrow cells of the rats treated by monosodium glutamate revealed structural and numerical chromosomal aberrations. Structural chromosomal aberrations noted in the current study were in the form of chromosomal gap (Chg), chromatid gap $(\mathrm{Cg})$, deletion $(\mathrm{D})$ and $\operatorname{ring}$ form $(\mathrm{R})$, centric fusion $(\mathrm{CF})$, fragment $(\mathrm{F})$ and centromeric attenuation $(\mathrm{Ca})$. When a cell contains at least three chromosomes with centromeric split, it was considered centromerically attenuated $(\mathrm{Ca})($ Fig. 6 B, C). The noticed numerical chromosomal aberrations were in the form of polyploidy (Fig. 6 D).The data collected after daily treatment with monosodium glutamate (400mg/Kg. b. w.) for 24 days revealed significant increase (at $\mathrm{P}<0.05)$ was observed in both of the number of structural chromosomal aberrations as [chromosomal gap and chromatid gap $(\mathrm{Chg}+\mathrm{Cg})$, Fragment (F) and Deletion(D)] and numerical chromosomal aberrations in the form of Polyploidy (Po) when compared with that of the control. Also, the total number of structural chromosomal aberrations were highly significantly increased $($ at $\mathrm{P}<0.01)$ in the treated group when compared with that of the control in the form of centromeric attenuation $(\mathrm{Ca})$, ring form (R) and centric fusion (CF). Table (2)

Group III (MSG + COS-NPs treated group): showed that the chromosomal aberrations were significantly decreased in the rats treated with combination of Chitosan nanoparticles plus MSG than those treated with MSG alone in the form of centric fusion (CF), ring form (R) and fragment (F). (Fig. 6 E). Table (3) showed that the percentage of chromosomal aberrations were significantly lesser $(P<0.05)$ in the group of rats treated with combination of Chitosan nanoparticles plus MSG than those treated with MSG alone. 


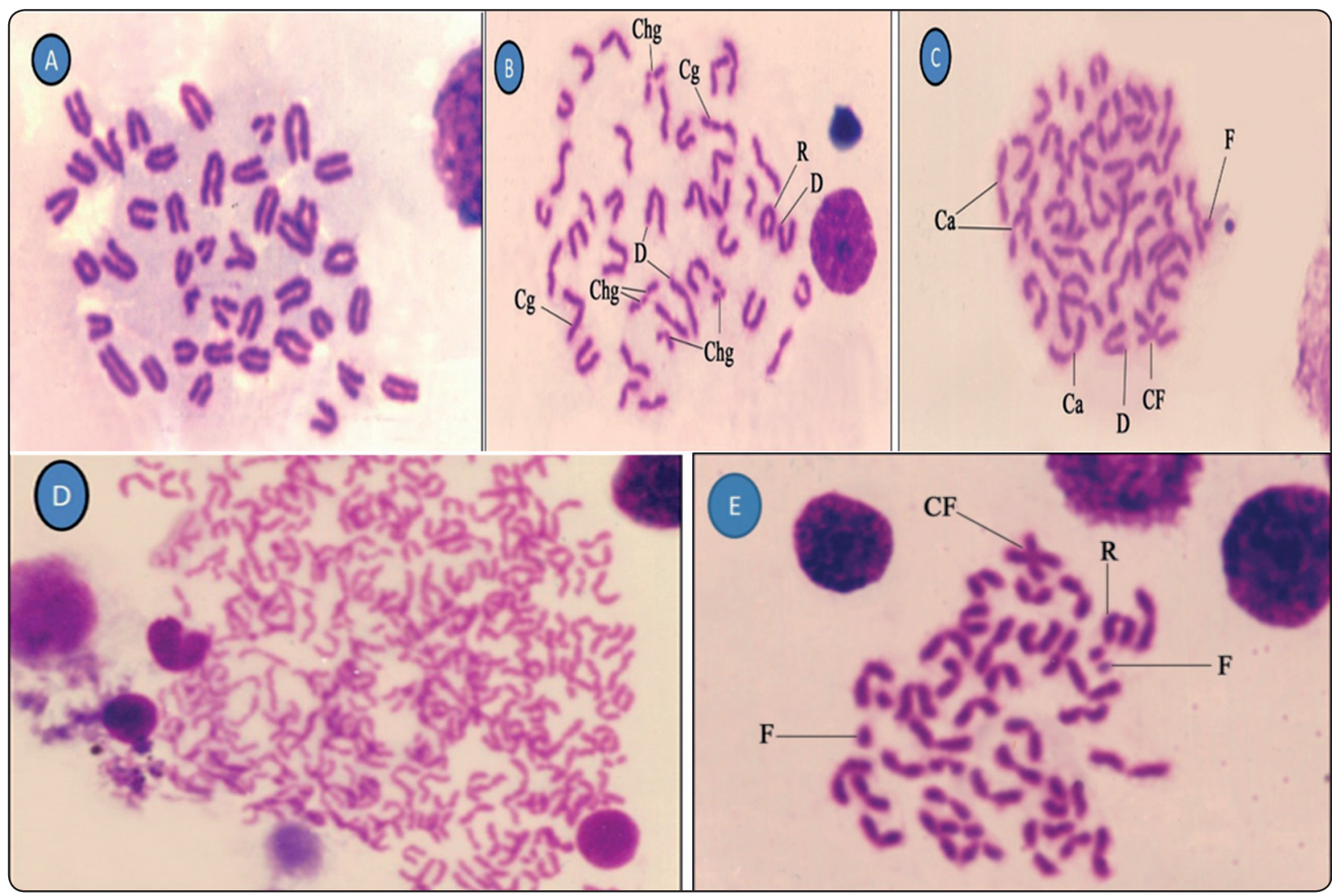

Fig.(6). A photomicrograph of metaphase spreading from rat bone marrow showing : (A) the group I (control) showing the diploid number of chromosomes $(2 \mathrm{n}=38+\mathrm{XY})$. All chromosomes are telocentric. (B,C,D) group II showing different types of chromosomal aberrations under MSG treatment for 21 days: chromosomal gap (Chg), chromatid gap (Cg), deletion (D) and ring form $(\mathrm{R})$, centric fusion $(\mathrm{CF})$, fragment $(\mathrm{F})$, centromeric attenuation $(\mathrm{Ca})$ and polyploidy. (E) group III rats treated with MSG plus Chitosan nanoparticles showing ring form (R), centric fusion (CF) and fragment (F). $\quad$ (X: 2500)

Table (2): The number and \% of chromosomal aberrations in metaphase cells of male albino rats treated with MSG (Group II) compared to the control (group I).

\begin{tabular}{|c|c|c|c|c|c|c|c|c|c|c|c|c|c|c|c|c|c|}
\hline \multirow{4}{*}{ Group } & \multirow{4}{*}{ 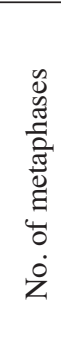 } & \multicolumn{12}{|c|}{ Structural aberrations } & \multirow{2}{*}{\multicolumn{2}{|c|}{$\begin{array}{l}\text { Numerical } \\
\text { aberrations }\end{array}$}} & \multirow{3}{*}{\multicolumn{2}{|c|}{$\begin{array}{c}\text { Total } \\
\text { aberrations }\end{array}$}} \\
\hline & & \multicolumn{8}{|c|}{ Chromosomal aberrations } & \multicolumn{4}{|c|}{ Chromatid aberrations } & & & & \\
\hline & & \multicolumn{2}{|c|}{$\begin{array}{c}\text { Centromeric } \\
\text { attenuation } \\
\text { (Ca) }\end{array}$} & \multicolumn{2}{|c|}{$\begin{array}{l}\text { Chromosome } \\
\text { gap and } \\
\text { chromatid gap } \\
(\mathrm{Chg}+\mathrm{Cg})\end{array}$} & \multicolumn{2}{|c|}{$\begin{array}{l}\text { Ring form } \\
\text { (R) }\end{array}$} & \multicolumn{2}{|c|}{$\begin{array}{c}\text { Centric } \\
\text { fusion } \\
(\mathrm{CF})\end{array}$} & \multicolumn{2}{|c|}{$\begin{array}{c}\text { Fragment } \\
\text { (F) }\end{array}$} & \multicolumn{2}{|c|}{$\begin{array}{l}\text { Deletion } \\
\text { (D) }\end{array}$} & \multicolumn{2}{|c|}{$\begin{array}{l}\text { Polyploidy } \\
\text { (Po) }\end{array}$} & & \\
\hline & & No. & $\%$ & No. & $\%$ & No. & $\%$ & No. & $\%$ & No. & $\%$ & No. & $\%$ & No. & $\%$ & No. & $\%$ \\
\hline Control & 500 & 3 & 0.6 & 3 & 0.6 & 4 & 0.8 & -- & -- & 2 & 0.4 & 4 & 0.8 & -- & -- & 16 & 3.2 \\
\hline $\begin{array}{l}\text { MSG } \\
\text { alone }\end{array}$ & 500 & $20^{* *}$ & 4 & $12^{*}$ & 2.4 & $14^{* *}$ & 2.8 & $15^{* *}$ & 3 & $12 *$ & 2.4 & $13^{*}$ & 2.6 & $8^{*}$ & 1.6 & 98 & 19.6 \\
\hline
\end{tabular}

** Highly significant $(P<0.01) *$ Significant $(P<0.05)$ 
TABLE (3): The number and \% of chromosomal aberrations in metaphase cells male albino rats treated with MSG + COS-NPs (Group III) compared to the control (group I).

\begin{tabular}{|c|c|c|c|c|c|c|c|c|c|c|c|c|c|c|c|c|c|}
\hline \multirow{4}{*}{ Group } & \multirow{4}{*}{ 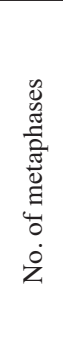 } & \multicolumn{12}{|c|}{ Structural aberrations } & \multirow{2}{*}{\multicolumn{2}{|c|}{$\begin{array}{l}\text { Numerical } \\
\text { aberrations }\end{array}$}} & \multirow{3}{*}{\multicolumn{2}{|c|}{$\begin{array}{c}\text { Total } \\
\text { aberrations }\end{array}$}} \\
\hline & & \multicolumn{8}{|c|}{ Chromosomal aberrations } & \multicolumn{4}{|c|}{ Chromatid aberrations } & & & & \\
\hline & & \multicolumn{2}{|c|}{$\begin{array}{c}\text { Centromeric } \\
\text { attenuation } \\
\text { (Ca) }\end{array}$} & \multicolumn{2}{|c|}{$\begin{array}{l}\text { Chromosome } \\
\text { gap and } \\
\text { chromatid gap } \\
\text { (Chg+Cg) }\end{array}$} & \multicolumn{2}{|c|}{$\begin{array}{l}\text { Ring } \\
\text { form } \\
\text { (R) }\end{array}$} & \multicolumn{2}{|c|}{$\begin{array}{l}\text { Centric } \\
\text { fusion } \\
(\mathrm{CF})\end{array}$} & \multicolumn{2}{|c|}{$\begin{array}{l}\text { Fragment } \\
\text { (F) }\end{array}$} & \multicolumn{2}{|c|}{$\begin{array}{c}\text { Deletion } \\
\text { (D) }\end{array}$} & \multicolumn{2}{|c|}{$\begin{array}{c}\text { Polyploidy } \\
\text { (Po) }\end{array}$} & & \\
\hline & & No. & $\%$ & No. & $\%$ & No. & $\%$ & No. & $\%$ & No. & $\%$ & No. & $\%$ & No. & $\%$ & No. & $\%$ \\
\hline Control & 500 & 3 & 0.6 & 3 & 0.6 & 4 & 0.8 & -- & -- & 2 & 0.4 & 4 & 0.8 & -- & -- & 16 & 3.2 \\
\hline $\begin{array}{c}\text { MSG + } \\
\text { COS-NPs }\end{array}$ & 500 & $11 *$ & 2.2 & 5 & 1 & 5 & 1 & 3 & 0.6 & 4 & 0.8 & 5 & 1 & - & - & 35 & 7 \\
\hline
\end{tabular}

** Highly significant $(P<0.01)$

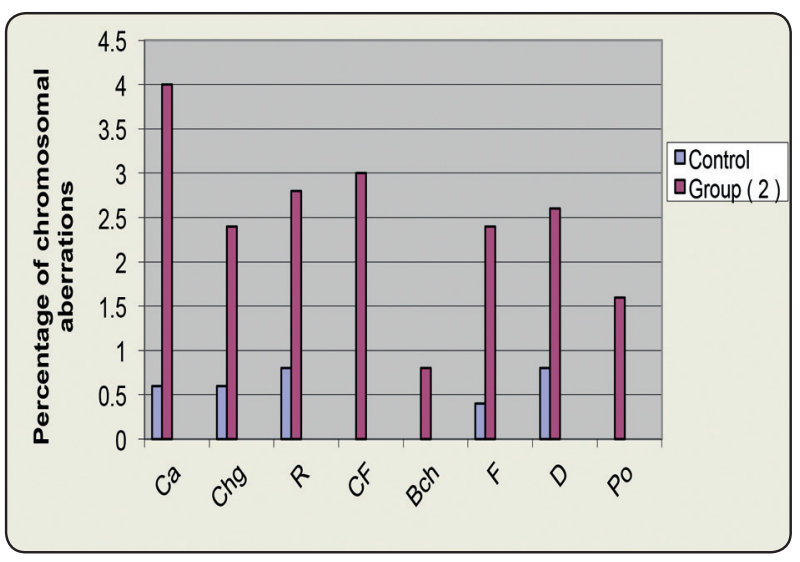

Fig. (7): Percentages of metaphase cells of rats treated with monosodium glutamate alone compared to the control.

\section{DISCUSSION}

MSG has got a popular flavor improvement in foods of recent communities and great number of Egyptians abusing it approximately everyday ${ }^{(30)}$. The present research revealed that MSG induced marked histopathological alterations, immunohistochemical changes in the submandibular salivary gland tissues and bone marrow chromosomal aberrations in rats. Regarding the histopathological changes; there were evidence of acini degeneration represented by disfigured lobular structure, cytoplasmic vacuolation and the secretory portions lost its normal architecture. The acinar cells showed nuclei

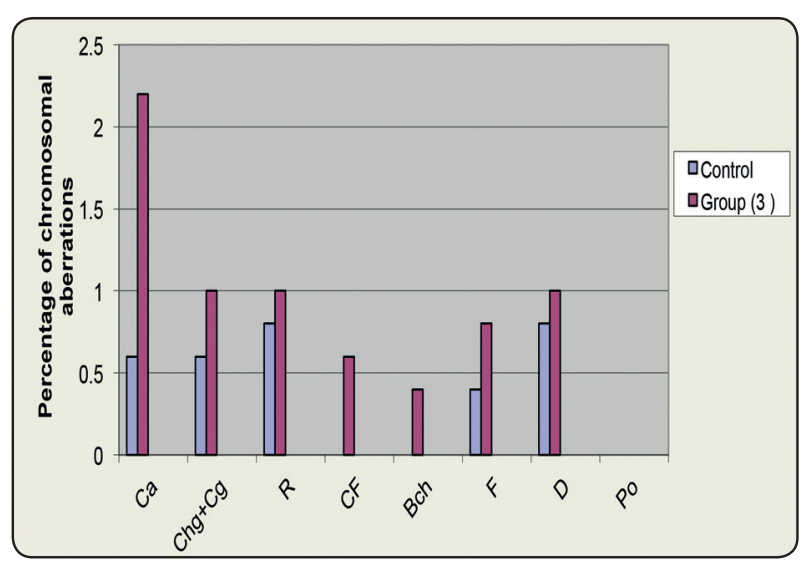

Fig. (8): Percentages of metaphase cells of albino rats treated with MSG + COS-NPs (Group III) compared to control.

with different sizes and shapes. Large dilated blood vessels appeared congested with blood were also detected. Our results matches other studies, proved that the gastric glands of MSG-treated rats were noticeably disorganized, expanded parietal cells with vacuolated cytoplasm, dilated and degenerated luminal epithelium, vesicular nuclei and significantly condensed chief cells with dark stained (pyknotic) nuclei ${ }^{(32)}$. These findings were agreed with other studies ${ }^{(12,34)}$ that reported similar follicular destruction of ovaries after MSG- treatment in rats. The degeneration of ovarian follicles was attributed to the increase of oxidative stress ${ }^{(4)}$. The induction of 
oxidative stress is caused by increasing production of reactive oxygen species (ROS), like hydrogen peroxide, superoxide anion and hydroxyl radicals ${ }^{(14)}$. Consequently, ROS could stimulate production of lipid peroxidation (LP) which is one of the major manifestations of oxidative damage that leads to toxicity and carcinogenicity. Moreover, ROS could suppress the cellular enzymes, depolymerize polysaccharides, and motivate deoxyribonucleic acid breaks and chromosome breakage which might explain the pleomorphic, pyknotic, hyperchromatic nuclei, structural and numerical chromosomal aberrations in our study. Our result also agreed with other studies which revealed nuclear hypertrophy of cell with damaged DNA were precisely corelated to biosynthetic activities of MSG in the myocytes of the human hypertrophic hearts such as DNA repair/synthesis, transcription power and translation competence ${ }^{(24)}$. Previous studies confirmed that MSG could stimulate the production of oxygen free radicals and oxidative stress, which increased lipid peroxidation, increased cytochrome c escape from the mitochondria to cytosol and also behaved as critical messenger for several pathological situations through exceeding cytosolic-free calcium. One possible mechanism of MSG is glutamate excitotoxicity that depended on an aggregation of glutamate in the synapses; overstimulation of both A-amino- 3-hydroxy-5- methyl-4isoxazolepropionate (AMPA) and metabotropic glutamate receptors might be elicited. The elevation of intracellular calcium levels consequently stimulates the calcium based degradative enzymes and apoptotic pathways ${ }^{(37,26)}$. Our findings of dilated and congested blood vessels come in co-ordinance with other studies reported dilated congested inter tubular blood vessels of testis in MSG treated rats (2). Congestion of blood vessels might be due to the inhibition of prostaglandin synthesis by MSG, as these compounds are known to be involved in regulation of blood flow ${ }^{(35)}$. Dilatation of salivary gland ducts might be due accumulation of toxins and ROS produced by MSG in their lining cells. The ill-defined form and obvious missing of pseudo-stratification of the excretory ducts lining of the submandibular salivary gland sections was attributed to loss of desmosomal junctions.

Apoptosis is a necessary physiological operation through which multi-cellular organisms could eliminate undesirable cells to confirm appropriate development and preserve cellular equilibrium. Caspases are sensitive mediators of programmed cell death (apoptosis) and represented as signs of apoptosis ${ }^{(28)}$. One of them; caspase-3 is a probably triggered death protease, stimulating the selected cleavage of numerous key cellular proteins, therefore caspase- 3 is known as a strong apoptotic marker ${ }^{(43)}$. Previously, it was documented that excessive consumption of MSG could exceed the cellular apoptosis via DNA fragmentation and suppression of Bcl-2 protein, where this component prohibit apoptosis through isolating proforms of death-driving cysteine proteases or caspases ${ }^{(41)}$. Our immunohistochemical results of submandibular salivary glands of MSG treated rats showed mild to strong caspase-3 immunoreactivity in the cytoplasm of submandibular salivary gland tissues which confirm the previous reports of increasing cell damage, DNA fragmentations and chromosomal aberrations under the influence of MSG treatment. Bone marrow cells were most frequently used for testing of mutagenicity and/or antimutagenicity characteristics of chemicals, because they are highly vulnerable to oxidative damage and most critical to clastogenic chemicals ${ }^{(58)}$. The current study, MSG resulted in structural aberrations like: chromosomal gap (Chg), chromatid gap (Cg), deletion (D) and ring form $(\mathrm{R})$, centric fusion $(\mathrm{CF})$, fragment $(\mathrm{F})$ and centromeric attenuation $(\mathrm{Ca})$ and numerical chromosomal aberrations in the form of polyploidy. Centromeric attenuation $(\mathrm{Ca})$ was the most common aberration, and is considered as an authenticated biomarker of cancer risk in humans. Our results were in harmony with other studies stated that MSG 
(50 mg/mL,100 mg/mL, $500 \mathrm{mg} / \mathrm{mL} ; 6$ and $24 \mathrm{~h}$ ) stimulate cytotoxicity and genotoxicity in Allium Cepa by causing chromosomal aberrations ${ }^{(44)}$. Also previous researches has demonstrated the genotoxic effects of MSG utilizing Allium Cepa assay (48). Roots of Allium Cepa were treated with 4 different concentrations $(0.01 \%, 0.005 \%, 0.1 \%$ and $0.5 \%)$ of MSG for 4 various time intervals $(1 / 2 \mathrm{~h}, 1 \mathrm{~h}, 2 \mathrm{~h}$ and $3 \mathrm{~h}$ ). An inhibitory effect has been shown on cell division and generalized reduction in mitotic index values in root tips that exposed to different concentrations of MSG . However, treatment with chitosan nanoparticles did not enhance the mean of structural chromosomal aberrations to the control level but there was significantly decrease in the number and percentage of centromeric attenuation (Ca). The current work showed the protective efficiency of chitosan nanoparticles against oxidative stress, cytotoxicity of submandibular salivary glands and genotoxicity in the form of chromosomal aberrations induced by monosodium glutamate in rat model was evaluated. Our results revealed significant improvement in both the histological picture of submandibular salivary gland tissue and DNA fragmentation in rats treated with chitosan nanoparticles. In the same concern, several studies reported that COS nanoparticles could suppress free radicals through its antioxidant properties, free radical scavenging activity and/or their capabilities to prevent lipid aggregation via its antilipidemic activity that indicates the chitosan nanoparticles could keep the stability of the cell membrane and consequently inhibit intracellular enzymes leakage to the blood ${ }^{(53)}$. Other studies reported that COS-NPs have anticancer activity ${ }^{(46)}$, antimutagenic $^{(64)}$ and immune-enhancing activity ${ }^{(61)}$ than those of chitosan. Another research indicated that COS-NPs could recover the activities of endogenous antioxidants and capable of attenuation hydrogen peroxide-causing stress damage in mouse macrophage ${ }^{(60)}$.

\section{CONCLUSION}

It could be concluded that the extensive consumption of MSG gave rise acute toxicity and oxidative stress in submandibular salivary gland as mentioned in our study by the histopathological disturbances, immunohistochemical changes and chromosomal aberration analysis. Treatment with COS-NPs succeeded in reduction these toxic impacts via its antioxidant properties and free radical scavenging characteristics of COS-NPs. As a drug delivery system, further studies are required to take advantages of chitosan and its derivatives as drug carriers have potential for a wider application.

\section{REFERENCES}

1. Abdel-Wahhab, M.A., Aljawish, A., El-Nekeety, A.A., Abdel-Aiezm, S.H., Abdel- Kader, H.A.M., Rihn, R.H., Joubert, O., 2015. Chitosan nanoparticles and quercetin modulate gene expression and prevent the genotoxicity of aflatoxin B1 in rat liver. Toxicol. Rep. 2, 737-747.

2. Alalwani AD. 2013. Monosodium glutamate induced testicular lesions in rats (histological study). Middle East Fertility Society J. 9(6):274-280.

3. Alao, O. A., Ashaolu, J. O., Ghazal, O. K. and Ukwenya, V. O. 2010. Histological and biochemical effects of monosodium glutamate on the frontal lobe of adult Wistar rats, International Journal of Biomedical and Health Sciences, 6(4): 197-203.

4. AL-Mosaibih, M.A., 2013. Effects of Monosodium Glutamate and Acrylamide on the Liver Tissue of Adult Wistar Rats. Life Science Journal., 10(2):35-42.

5. Andrew OE., 2007. Histological studies of the effects of monosodium glutamate on the kidney of adult Wistar rats. The Internet Journal of Health. 6(2).

6. Bhattacharya, T., Bhakta, A. and Ghosh, S.K., 2011: Long term effect of monosodium glutamate in liver of albino mice after neonatal exposure, Nepal Medical College Journal, 13(1): 11-16.

7. Bojanic, V., Bojanic, Z., Najman, S., Savic, T., Jakovljevic, V., Najman, S., Jancic, S. 2009. Diltiazem prevention of toxic effects of monosodium glutamate on ovaries in rats. Gen Physiol Biophys., 28:149-54. 
8. Cao J, Zhou NJ., 2005. Progress in antitumor studies of chitosan. Chin J Biochem Pharm.; 26(2):127-127.

9. Chen, A.S., Taguchi, T., Sakai, K., Kikuchi, K.,Wang, M.W., Miwa, I., 2003. Antioxidant activities of chitobiose and chitotriose. Biol. Pharm. Bull. 26, 1326-1330.

10. El-Denshary, E.S., Aljawish, A., El-Nekeety, A.A., Hassan, N.S., Saleh, R.H., Rihn, B.H., Abdel-Wahhab, M.A., 2015. Possible synergistic effect and antioxidant properties of chitosan nanoparticles and quercetin against carbon tetrachlorideinduce hepatotoxicity in rats. Soft Nanosci. Lett. $5,36-51$.

11. Eweka AO and Adjene JO. Histological Studies of the Effects of Monosodium Glutamate on the Medial Geniculate Body of Adult Wistar Rats. Electron J Biomed 2007; 2:9-13.

12. Eweka, A.O., Om'iniabohs, F.A.E., 2011. Histological studies of the effects of monosodium glutamate on the ovaries of adult wistar rats. Ann Med. Health Sci. Res., $2,1: 37-44$

13. Geha, R., Beiser, A., Ren, C., Patterson, R., Grammer, L., Ditto, A.M, Harris, K.E., Shaughnessy, M.A., Yarnold, P.R., Corren. J., Saxon, A., 2001. Review of allergic reaction to monosodium glutamate and outcome of a multicenter double blind placebo-controlled study. J Nutr., 130:1032-8.

14. Goldstein, R.S. Schellmann R.G. (1995): Toxic responses of the kidney. In: casarett and Doull's Toxicology. The Basic Science Of Poisons, ed., Klaassen CD, 5 th ed., pp 417442, McGraw-Hill companies Inc., New York, NY.

15. Hamza RZ and AL-Harbi MS., 2014. Monosodium glutamate induced testicular toxicity and the possible ameliorative role of vitamin E or selenium in male rats. Toxicology Reports. 1: 1037-1045.

16. Huang, R., Mendis, E., Kim, S.K., 2005. Factors affecting the free radical scavenging behavior of chitosan sulfate. Int. J. Biol. Macromol. 36, 120-107.

17. Hui, A., Furong, W., Yuqi, X., Xiaomin, C., Chaoliang, L., 2012. Antioxidant, antifungal and antiviral activities of chitosan from the larvae of housefly, Musca domestica L. Food Chem. 132, 493-498.

18. Huo S, Xu Z, Zhang X, Zhang J, Cui S., 2010. Testicular denervation in prepuberty rat inhibits seminiferous tubule development and spermatogenesis. J Reprod Dev.56: 370-8.
19. Huthman I, Shoyebo O, Akinbowale O, Ajayi R, Huthman A, Adenowo T, Adefule A. Monosodium Glutamate: A Good Replacement For Hydrogen Peroxide In Bone Preparations. The Internet Journal of Biological Anthropology 2009; Volume 4 Number 1:1-7.

20. Je, J.Y., Park, P.J., Kim, S.K., 2004. Free radical scavenging properties of heterochito-oligosaccharides using an ESR spectroscopy. Food Chem. Toxicol. 42, 381-387.

21. Jia, L., 2005. Nanoparticle formulation increases oral bioavailability of poorly soluble drugs: approaches experimental evidences and theory. Curr. Nanosci. 1 (3):237-243.

22. John AH., 1973. A rapid in vivo test for chromosomal damage. Mut. Res., 18: 187-190.

23. Kaitano TE., 2014. Food additives: Flavors and Flavor Enhancers. Monosodium L-glutamate in: Encyclopedia of Food Safety. Edited by Motarjemi Y, Moy G, Todd E, Academic Press, $1^{\text {st }}$ edition: 468.

24. Koda M, Takemura G, Okada H, Kanoh M, Maruyama R, Esaki M, Li Y, Miyata S, Kanamori H, Li L, et al., 2006. Nuclear hypertrophy reflects increased biosynthetic activities in myocytes of human hypertrophic hearts. Circ J. 70(6):710-8.

25. Kohda, N., Inoue, S., Noda, T., Saito, T., 2012. Effects of a chitosan intake on the fecal excretion of dioxins and fat in rats. Biosci. Biotechnol. Biochem. 76, 1544-1548.

26. Kumar P, Bhandari U. 2013. Protective effect of Trigonella foenum-graecum Linn. On monosodium glutamate induced dyslipidemia and oxidative stress in rats. Indian $\mathrm{J}$ Pharmacol. 45:136- 40.

27. Leung, A. and Foster, S., 1996: "Encyclopedia of Common Natural Ingredient Used in Food," Drugs and Cosmetics, New York, Wiley, 373-375.

28. Logs, M., W., Esselborg, S., Scqhulze-Osothoff, K. (1999). The role of caspases in development, immunity, and apoptotic signal transduction: lessons from knockout mice. Immunity., 10:629-39.

29. Luo, X.L., Xu, J.J., Du, Y., Chen, H.Y., 2004. A glucose biosensor based on chitosan glucose oxidase-gold nanoparticles biocomposite formed by one-step electrodeposition. Anal. Biochem. 334, 284-289.

30. Mohamed IK., 2012. The effects of oral dosage of monosodium glutamate applied for short- and long-terms on the histology and ultrastructure of testes of the adult rats. J. Anim. Vet. Adv, 11(1): 124- 133. 
31. Moore, K.L. 2003. Congenital malformations due to environmental. Developing human. 2nd ed. Philadelphia: W.B. Saunders Co. Ltd.,173-83.

32. Morsy M.M., Hassanein G.H.E., Farag AI., 2016. Effect of Monosodium Glutamate administration on Gastric Mucosa of Adult Male Albino Rat: A Histological, Immuno histochemical and Histomorphometric Study. Nat Sci;14(12):134-141.

33. Nam, K.S., Kim, M.K., Shon, Y.H., 2007. Chemopreventive effect of chitosan oligosaccharide against colon carcinogenesis. J. Microbiol. Biotechnol. 17, 1546-1549.

34. Oforofuo, I.C.,Adebayo, E.A., Kuye, O.M. (2015). Effects of Monosodium Glutamate in Ovaries of Female SpragueDawley Rats Int.J.Curr.Microbiol.App.Sci., 4(5): 737-45.

35. Oladipo IC, Adebayo EA \& Kuye OM. 2015. Effects of monosodium glutamate in ovaries of female sprague-dawley rats. Int. J. Curr. Microbiol. App. Sci. 4(5):737-745.

36. Onakewhor, J., Oforofuo, I., Singh, S . (1998). Chronic administration of monosodium glutamate induces oligozoospermia and glycogen accumulation in Wistar rat testes. Afr J Reprod Health.,2(2):190-7.

37. Onyema OO, Aisil CS, Ihetuge AP. 2012. Monosodium Glutamate Induces Oxidative Stress and Affects Glucose Metabolism in the Kidney of Rats. International Journal of Biochemistry Research \& Review. 2(1):1-11.

38. Ortiz GG, Bitzer-Quinter OK, Beas Zárate C, RodríguezReynoso S, Larios-Arceo F, Velázquez- Brizuela IE, Pacheco-Moisés F and Rosales- Corral SA. Mono-sodium glutamate-induced damage in liver and kidney: a morphological and bio-chemical approach. Biomed Pharmacother 2006; 60: 86-91.

39. Park, P.J., Je, J.Y., Byun, H.G., Moon, S.H., Kim, S.K., 2004. Antimicrobial activity of hetero chitosans and their oligosaccharides with different molecular weights. Mol. Microbiol. Biotechnol. 14, 317-323.

40. Patel, V.R. and Agrawal, Y.K., 2011. Nanosuspension: An Approach to Enhance Solubility of Drugs. Journal of Advanced Pharmaceutical Technology and Research, 2, 81-87.

41. Pavlovic, V., Cekic, S., Kocic, G., Sokolovic, D., Zivkovic, V. 2007. Effect of Monosodium Glutamate on Apoptosis and Bcl-2/ Bax Protein Level in Ra Thymocyte Culture. Physiol. Res. 56: 619-626.

42. Pavlovic V., Sarac M. 2010. Topical Review: The role of ascorbic acid and monosodium glutamate in thymocyte apoptosis. Bratisl Lek Listy. 111 (6): 357 - 360.
43. Porter, A.G., Janicke, R.U.1999. Emerging roles of caspase-3 in apoptosis, Cell Death and Diffe; 6: 99- 104.

44. Prasath, D., Muthu, S., Surya. 2013. Detection of genotoxicity and chromosomal aberrations induced by Furadan and Monosodium glutamate in Allium Cepa. Biol. Sci. 3(1): 11-24.

45. Preston, J.R., Brian, J.D. and Sheila, G., 1987. Mammalian in vivo cytogenetic assays, Analysis of chromosomal aberrations in mouse bone marrow cells. Mut. Res., 189: 157-165.

46. Qi, L., Xu, Z., Chen, M., 2007. In vitro and in vivo suppression of hepatocellular carcinoma growth by chitosan nanoparticles. Eur. J. Cancer 43 (1), 184-193.

47. Ragelle H, Riva R, Vandermeulen G, Naeye B, Pourcelle V, Le Duff CS, D'Haese C, Nysten B, Braeckmans K, De Smedt SC., 2014. Chitosan nanoparticles for siRNA delivery: optimizing formulation to increase stability and efficiency. Journal of Controlled Release. 176: 54-63.

48. Renjana, P.K., Anjana, S., Thoppil, J.E., 2013. Evaluation of genotoxic effects of baking powder and monosodium glutamate using Allium Cepa assay. Int, J. Pharm. Sci. 5(2): 311-315.

49. Samuels, A. 1999. The Toxicity/Safety of MSG: A Study in Suppression of Information. Accountability in Research, 6(4): 259-310.

50. Santosh, K., Joonseok, K., Hyerim, K., Gupta, M.K., Dutta, P.K., 2012. A new chitosan thymine conjugates: synthesis, characterization and biological activity. Int. J. Biol. Macromol. 50 (3), 493-502

51. Schwerin, P., Bessman, S.P. and Waelsch, H., 1950: The uptake of glutamic acid and glutamine by brain and other tissues of the rat and mouse, J. Biol. Chem., 184: 37-44.

52. Singh K and Ahluwalia P. Studies on the effect of Monosodium Glutamate (MSG) administration on some antioxidant enzymes in the arterial tissue of adult male mice, $\mathrm{J}$. Nutr. Sci. 49:145, 2003.

53. Sivakumar, R., Rajesh, R., Buddhan, S., Jeyakum, R., Rajaprabhu, D., Ganesan, B., Anandan, R., 2007. Antilipidemic effect of chitosan against experimentally induced myocardial infarction in rats. J. Cell. Anim. Biol. 1 (4), 071- 077.

54. Sze, A., Erickson, D., Ren, L., Li, D., 2003. Zeta-potential measurement using the Smoluchowski equation and the slope of the current-time relationship in electroosmotic flow. J. Colloid Interface Sci. 261, 402-410. 
55. Tang, Z.X., Qian, J.Q., Shi, L.E., 2007. Preparation of chitosan nanoparticles as carrier for immobilized enzyme. Appl. Biochem. Biotechno 136, 77-96.

56. Tawfik, M.S., Al-Badr, N. 2012. Adverse Effects of Monosodium Glutamate on Liver and Kidney Functions in Adult Rats and Potential Protective Effect of Vitamins C and E. FNS., 3: 651-659.

57. Ukun, Q., Ronge, X., Song, L., Kecheng, L., Xiangtao, M., Rongfeng, L., Jinhui, C., Bing, L., Pengcheng, L., 2012. Novel thiosemicarbazone chitosan derivatives: preparation, characterization and antifungal activity. Carbohydr. Polym. 87, 2664-2670.

58. Umegaki, K., H. Uramoto and T. Esashi, 1997. Lack of influence of a long-term high or low vitamin E diet on the oxidative DNA damage in the bone marrow of mice. Int. J. Vitamin Nutr. Res., 67: 149-154.

59. Waer, H.F., Edress, E. 2006. The Effect of Monosodium Glutamate (MSG) On Rat Liver And The Ameliorating Effect Of "Guanidino Ethane Sulfonic acid (GES)" (Histological, Histochemical and Electron Microscopy Studies). Egyp. J Hosp. Med., 24:524 - 538.

60. Wen, Z.S., Liu, L.J., Qu, Y.L., Ou Yang, X.K., Yang, L.Y., Xu, Z.R., 2013. Chitosan nanoparticles attenuate hydro- gen peroxide-induced stress injury in mouse macrophage RAW264 7 Cells. Mar. Drugs 11 (10), 3582-3600.

61. Wen, Z.S., Xu, Y.L., Zou, X.T., Xu, Z.R., 2011. Chitosan nanoparticles act as an adjuvant to promote both Th1 and Th2 immune responses induced by ovalbumin in mice. Mar. Drugs 9 (6), 1038-1055.

62. Yong, L., Yongzhen, L., Mingzhe, L., Puwang, L., Lei, W., 2011. Preparation and characterization of novel curdlan/ chitosan blending membranes for antibacterial applications. Carbohydr. Polym. 84, 952-959.

63. Yousef, J.M., 2011.Study the impacts of monosodium glutamate (MSG) and extract of green tea (theaceae family) leaves induced on kidney biochemical functions in rats. Int J Acad Res., 3:108-12.

64. Yu, Z.B., Chai, D.R., Tao, H., 2007. Antagonism of nanochitosan against mutagenic effect of different mutagens to Salmonella Typhinurium. Occup. Health 19, 004-009.

65. Zerasky, K., 2010. Nutrition and healthy eating; monosodium glutamate: is it harmful? Available at: http://www.mayoclinic.

66. Zia, M.S., Qamar, K., Hanif, R., Khalil, M., 2014. Effect of monosodium glutamate on the serum estrogen and progesterone levels in female rat and prevention of this effect with diltiazem. J Ayub Med Coll Abbottabad., 26(1):18-20. 